NBER WORKING PAPER SERIES

\title{
UNDERSTANDING INDIVIDUAL ACCOUNT GUARANTEES
}

\author{
Marie-Eve Lachance \\ Olivia S. Mitchell \\ Working Paper 9195 \\ http://www.nber.org/papers/w9195 \\ NATIONAL BUREAU OF ECONOMIC RESEARCH \\ 1050 Massachusetts Avenue \\ Cambridge, MA 02138 \\ September 2002
}

The authors are grateful for comments provided by Zvi Bodie, Neil Doherty, Alex Muermann, and Kent Smetters. They also benefited from research support provided by the Michigan Retirement Research Center, the Shannon Schieber Memorial Fund, and the Society of Actuaries (Lachance); the Pension Research Council (Mitchell); and the Department of Insurance and Risk Management at the Wharton School of the University of Pennsylvania (both authors). The views expressed herein are those of the authors and not necessarily those of the National Bureau of Economic Research.

(C) 2002 by Marie-Eve Lachance and Olivia S. Mitchell. All rights reserved. Short sections of text, not to exceed two paragraphs, may be quoted without explicit permission provided that full credit, including (C) notice, is given to the source. 
Understanding Individual Account Guarantees

Marie-Eve Lachance and Olivia S. Mitchell

NBER Working Paper No. 9195

September 2002

JEL No. G2, H4, J1, I3

\begin{abstract}
$\underline{\text { ABSTRACT }}$
Demographic aging renders workers vulnerable to the inherent uncertainty of unfunded social security systems. This realization has set off a global wave of social security reforms, and numerous countries have now set up Individual Accounts (IA) plans in response. Strengths of IAs are that participants gain ownership in their accounts, and they also may diversify their pension investments; additionally, they produce a capitalized, funded system that enhances old-age economic security. While IAs reduce the risk participants face due to unfunded social security systems, participants holding capital market investments in IAs are exposed to fluctuations in the value of their pension assets. Concern over market volatility has prompted some to emphasize the need for "guarantees" of pension accumulations. This paper offers a way to think about guarantees in the context of a social security reform that includes Individual Accounts. When a pension guarantee has economic value to participants, it will have economic costs. We illustrate how these costs can be important and vary significantly with time horizon, investment mix, and guarantee design. Our findings indicate that plan designers and budget analysts would do well to recognize such costs and identify how they can be financed.
\end{abstract}

Marie-Eve Lanchance

Department of Insurance and Risk Management Wharton School, University of Pennsylvania 3641 Locust Walk

Philadelphia, PA 19104

malachan@wharton.upenn.edu
Olivia S. Mitchell

Professor of Insurance and Risk Management Wharton School, University of Pennsylvania 3641 Locust Walk, Rm 304 CPC

Philadelphia, PA 19104

and NBER

mitchelo@wharton.upenn.edu 


\section{Understanding Individual Account Guarantees \\ Marie-Eve Lachance and Olivia S. Mitchell}

Demographic aging is prompting workers everywhere to realize that they are vulnerable to the inherent uncertainty that arises from unfunded social security systems. This realization has prompted a global wave of social security reforms, resulting in over 20 countries setting up Individual Account (IA) plans. Interest in this movement has recently gained strength in the United States with the release of the President's Commission to Strengthen Social Security (CSSS) Final Report, in which voluntary individual accounts (IAs) are proposed as a component of a reformed system. ${ }^{1}$

Key strengths of IAs are that participants gain ownership in their accounts and may diversify their pension investments. But in view of the recent demise of Enron, some have argued that access to capital market investments might impose new risk on IA participants. ${ }^{2}$ Concern over capital market volatility has consequently prompted some policymakers to propose "guarantees" for defined contribution pension accumulations. ${ }^{3}$ Abroad, such guarantees have already been adopted in several Latin American countries undergoing reform, ${ }^{4}$ and more recently, in Japan and Germany. ${ }^{5}$

The purpose of this paper is to illustrate how one might evaluate pension guarantees in the context of an Individual Account component of a social security reform. ${ }^{6}$ Our contention is that if a pension guarantee has economic value to the participant, it must also have an economic cost. Plan designers and budget analysts should recognize such costs and identify how they can

\footnotetext{
${ }^{1}$ See President's Commission to Strengthen Social Security Final Report (2001; www.csss.gov).

${ }^{2}$ See Jickling (2002) for an overview of the financial issues surrounding the Enron collapse, and Mitchell and Utkus (2002) on company stock in retirement plans.

${ }^{3}$ See, for instance, Benson (2001).

${ }^{4}$ Zarita (1994), Fischer (1999), and Pennachi (1999, 2000) discuss Latin American pension guarantees.

${ }^{5}$ See Clark and Mitchell (2002) for Japan, and Maurer and Schlag (2002) for Germany.

${ }^{6}$ Here we focus only on the accumulation phase of Individual Accounts, and not the decumulation phase.
} 
be financed. Public policy that proposes new guarantees must identify who will pay for them and why.

In what follows, Section I surveys the major guarantee designs adopted or suggested in a social security context. Section II provides the background necessary to analyze guarantee costs. Section III provides five examples of guarantee designs and their cost estimates, using the methodology and assumptions developed in the Appendix. Section IV discusses alternative financing options for the pension guarantee, and Section V concludes.

\section{An Overview of Pension Guarantees}

While many alternative pension guarantee mechanisms could be envisaged, they may be classified into two general categories: minimum rate of return guarantees, and minimum benefit guarantees.

Under a minimum rate of return guarantee, plan participants would be entitled to receive payments at least equal to their lifetime contributions to the system plus some rate of return. One variant on this theme is a "principal guarantee" which is equivalent to guaranteeing a nominal rate of return of zero percent. This approach has been adopted recently in Germany and Japan, such that participants must receive at least their plan contributions at retirement (but not before). A more generous design proposed by Feldstein and Samwick (2001) involves a "real principal guarantee," under which participants would be guaranteed their lifetime contributions adjusted according to an inflation index. Still a more generous guarantee might promise participants their contributions plus some minimum rate of return. For example, participants could be told that 
they would always receive their contributions plus the return on a government bond (e.g. the 10year Treasury bond. $)^{7}$

Irrespective of the particular guaranteed rate of return adopted, its cost will depend in part on how often the guarantee threshold is tested. In many designs, as in the German and Japanese cases, the guarantee is evaluated only once, at the end of the plan participant's worklife. In other instances, the minimum rate of return is imposed annually. In Uruguay, for instance, the investment-based system provides pension participants a minimum annual real rate of return of 2 percent. In Chile, pension funds must pay an annual real rate of return that is a function of the average annual real rate of return earned by the entire set of pension funds. Finally, in Colombia, the guaranteed rate of return is evaluated over three-year periods (Pennachi, 1999; Fischer, 1999).

A prominent alternative to a minimum rate of return guarantee is a minimum benefit guarantee. In this second approach, plan participants are promised that the benefits they will receive from social security at retirement will be at least as high as a minimum annuity, irrespective of their account's actual investment performance. For instance, the Chilean reform provides a "minimum annuity" to defined contribution participants, financed by a pay-as-you-go program (Zarita, 1994; Pennachi, 1999). Some social security systems have adopted a multipillar structure of benefits in which the participant receives the combination of a defined benefit annuity (first-pillar) and an Individual Account (second-pillar). Under this design, evaluating possible program costs must take into account the sum of these benefits, and compare them to the minimum annuity. In the US context, Feldstein and Samwick (2001) describe a "mixed" system where part of the participant's social security tax is contributed to an Individual Account

\footnotetext{
${ }^{7}$ The DeMint-Armey plan, for instance, guarantees benefits for those who elect a balanced Individual Account portfolio, but no additional value is assigned to either the guarantee or the cost of providing a minimum benefit under government cost estimates.
} 
while the remainder is used to finance the pay-as-you-go program. Their suggested model also includes a guarantee that participants would receive benefits at least as great as under the present law benefit formula. ${ }^{8}$

\section{The Moral Hazard Issue}

In addition to the guarantee formulas described above, another factor influencing the value of the guarantee is the level of investment risk taken by the Individual Account participant. Participants may boost the value of the guarantee, if they elect to hold riskier investments in their portfolios. Naturally this can give rise to a moral hazard problem, as recognized by Bodie and Merton (1993) and Smetters (2002), among others.

Several tools are available to address the moral hazard problem. One would be to specify a standard investment portfolio and provide the guarantee only to those participants who elected that standard portfolio. Another approach would let participants invest in the portfolio of their choosing, but then guarantee payments would be computed using the standard portfolio as a benchmark, rather than the participant's actual investment returns. This second approach leaves participants with more investment flexibility, though it would not protect them against investment risk greater than experienced by the standard portfolio.

\section{Models for Valuing Pension Guarantees}

This section models guarantee outcomes under the two approaches outlined above, and it further illustrates likely guarantee costs using financial techniques for determining the economic value of guaranteed pension payments.

\section{Guaranteeing Retirement Income}

\footnotetext{
${ }^{8}$ Smetters (2001) analyses various alternative specifications for this type of guarantee, in the context of a complete conversion to Individual Accounts.
} 
It is useful to develop a simple notation for valuing both the minimum rate of return and minimum benefit guarantee approaches. Denote by $T$ the number of years over which a plan participant contributes to his IA. For a young worker (i.e. a new system participant), the period $T$ corresponds to the length of the full worklife. By contrast, when the system is first introduced, a more senior worker would have a much shorter window during which he could contribute to his Individual Account. Further, let $I A_{T}$ and $G_{T}$ denote, respectively, the value of the IA and of a given guarantee formula at retirement.

The guarantee payments can then be specified depending on the account's investment result. No guarantee is paid at retirement if, at that time, the Individual Account accumulation exceeds the value of the guarantee: $I A_{T}>G_{T}$. But if the value of the Individual Account is below the guaranteed minimum, then the guarantee payment must cover the difference (i.e. $\left.G_{T}-I A_{T}\right)$. The guarantee payoffs, illustrated in Figure 1, may be represented as follows:

$$
f_{T}=\max \left[0, G_{T}-I A_{T}\right]
$$

Figure 1 here

It must be noted that equation (1) is applicable in the case of a newly-created IA system, with no legacy commitment from a prior system. More generally, individual account models sometimes develop after a partial or full conversion from a prior pay-as-you-go program. Under a full conversion, the participant would receive the sum of his IA and (possibly) an additional benefit reflecting his participation under the legacy system. Under a partial conversion (or "mixed" system), the participant would receive a combination of his Individual Account and also a defined benefit component as specified under the old plan, perhaps subject to adjustment. Thus under a minimum benefit guarantee, it is necessary to adjust equation (1) by adding to the Individual Account value any additional benefits. 
To illustrate this point, we examine how one might adjust equation (1) for a "mixed" reform. Under the current US social security system, for instance, workers are promised a retirement annuity with present value, $S S_{T}$. If voluntary IAs were to be permitted, participant would likely be allowed to divert a portion (but not all) of their social security contributions to a funded defined contribution pension account. To compensate the Trust Fund for the loss in contributions, the promised social security annuity would have to be reduced by an offset amount. The President's Commission (2001) proposed to calculate such an offset by asking, in effect, how much Individual Account contributions would be expected to accumulate under a given rate of return. Letting $O f f s e t_{T}$ and $S S_{T}^{R E D}$ represent, respectively, the offset and the reduced annuity, then a minimum benefit guarantee for a "mixed" social security system can be represented by:

$$
f_{T}=\max \left[0, G_{T}-\left(I A_{T}+S S_{T}^{R E D}\right)\right] \text {, }
$$

or equivalently,

$$
f_{T}=\max \left[0, G_{T}-\left(I A_{T}+\left(S S_{T}-\text { Offset }_{T}\right)\right)\right] .
$$

Finally, we note that in (2) and (3), social security benefits are assumed to be paid with certainty. Potential costs associated with the funding of social security benefits should be handled separately; that is, legacy system costs are properly attributed to the old system, and not to the guarantee. $^{9}$

\section{Valuing Guarantee Payoffs with Option Pricing Techniques}

The discussion above shows that a guarantee can provide value to plan participants since investors receive some floor of protection against the chance of a capital market loss. It follows that the value of a guarantee must represent a liability to the sponsor, be it a private sector group

\footnotetext{
${ }^{9}$ The President's Commission to Strengthen Social Security identified several alternative ways to handle legacy costs (www.csss.gov).
} 
- a plan sponsor, an insurer, a financial services firm - or a government entity. Over the last decade, as a result of experience with the Savings and Loan crisis as well as other government guarantee programs, the Congressional Budget Office (CBO) and the General Accounting Office (GAO) have increasingly taken the position that government guarantees should be evaluated and costed as to their budgetary impact. If a pension guarantee were to be included in an IA plan proposal, it would be necessary to estimate and recognize the financial cost of such a promise. That is, irrespective of whether guarantees are provided by a government entity or private sector firms, it is essential to account properly for their costs since real economic resources are required to finance them.

Unfortunately there is much confusion regarding the economic value of such costs, due in part to the fact that some seek to compute guarantee values with risk adjustments, while others do not. Further, some approaches use projected expected guarantee payments, while others discount these payments to the time of the valuation. Finally, some propose that the value of guarantees depends on whether the government or private insurers bear them. While alternative approaches might be valid depending on the use to which they are put, here we propose to define guarantee costs such that the values generated indicate true economic resource costs. If the guarantee commitment were made to capital market investors, the value of the guarantee could be determined by using option pricing techniques, and a "market value" approach for the guarantee could be derived. Since the nature of the counterparty should not influence the economic value of the liability, the approach used with capital market investors should also be valid with social security participants.

One way to think about this is to recognize that the shape of guarantee payments in Figure 1 conforms to a "put option." This option covers the shortfall, if any, between the value 
of a stock and a strike price. Put options are commonly valued using the well-known BlackScholes (1973) formula which relies on a "no-arbitrage" argument. Since put option payoffs can be replicated by continuously rebalancing a mix of the underlying stock and a bond, the value of such a put option must equal the market price of this replicating portfolio.

In the pension case, the IA participant invests a series of contributions over the entire worklife, rather than at a single time in a lump sum; as a result, the Black-Scholes formula cannot be applied directly. Instead, the problem can be solved by applying a more flexible noarbitrage technique called "risk-neutral valuation". ${ }^{10}$ Implementing the technique in the current context requires three steps. First, the probability distributions of the underlying securities are adjusted for risk. This probability adjustment is made such that risk-adjusted return processes are expected to yield the risk-free rate. Expectations taken with these risk-adjusted probabilities are represented by the operator $\hat{E}$. Second, using the appropriate formulas, the guarantee payments are projected to time $T$ and discounted back at the risk-free rate. Third, the value of the pension guarantee is obtained by taking the risk-adjusted expected value of the discounted guarantee payments.

The process may be summarized analytically in equation (4) below. Letting $\bar{r}$ represent the average risk-free rate over the period, the no-arbitrage value $f$ of a derivative that pays $f_{T}$ at time $T$ is given by:

$$
f=\hat{E}\left[\exp (-\bar{r} T) f_{T}\right]
$$

Deriving an analytical solution for (4) in the guarantee case requires an analytical expression for the probability distribution of the IA. In the Black-Scholes framework with a single purchase, the underlying stock growth process is assumed to be lognormal. In the Individual Account

\footnotetext{
${ }^{10}$ This technique is found in standard finance textbooks (Duffie, 1996; Hull, 1997) and is also referred to as "martingale pricing".
} 
framework, each year's contribution may be assumed to grow according to a lognormal distribution, but the sum of these contributions is not lognormal nor does it have a meaningful analytical representation. Hence we evaluate equation (4) numerically using Monte Carlo simulation, used below to illustrate the costs of several guarantee options. ${ }^{11}$

\section{Nature of the Downside Risk}

As was shown above, having a pension guarantee is potentially valuable because of the "downside risk" inherent in IA investments. It is interesting that popular belief regarding the nature of this downside risk tends to downplay the value of such guarantees. For instance, it is often recommended that investors with long investment horizons hold a larger proportion of stocks in their portfolios. This view is grounded in the argument that stocks are less risky in the long run or, putting it another way, that investors have more time to recoup their losses with longer investment horizons. Historically, stocks have outperformed bonds over long investment horizons, ${ }^{12}$ so the belief is that this trend will repeat in the future, resulting in costless guarantees. Empirical evidence on this point is provided in Figure 2, which graphs historical annual nominal returns payable to short-term investors in US stock and bond indexes over the period 1942-2000. The figure confirms that in the US, at least, stock returns have historically exceeded bond returns, but with higher volatility. Over the period, the average annual (nominal) return was 14.6 percent on a stock index fund (S\&P 500) compared to an average bond fund return of 5.8 percent. The volatility of the stock index over the same period was also higher, at 16.5 percent, compared to bond volatility of 9 percent. (Asset volatility is conventionally measured by the standard deviation of historical returns around the mean). These data illustrate the so-called "equity premium" - that is, because stocks (equities) are seen by the market as more volatile and

\footnotetext{
${ }^{11}$ This approach makes no assumptions regarding any particular IA participant's risk aversion; in particular, workers are not required to be neutral in their preferences for risk for the cost estimates to hold.

${ }^{12}$ See for example Siegel (1998) on the relative historical performances of stocks and bonds.
} 
hence riskier than bonds, purchasers of stocks require an additional risk premium or return in order to hold them.

Figure 2 here

While all would agree that higher volatility means more risk for short-term holding periods, there is more controversy over returns on assets over longer period. Figure 3 illustrates the volatility of stock returns for longer investment horizons, using the same underlying data as Figure 2 but now expressing the volatility of total returns over periods between and 30 years. What becomes clear is that the annualized stock returns become less volatile over time, but the opposite is true for compounded stock returns. ${ }^{13}$ Applied to the guarantee context, these findings imply that the volatility of IA accounts should increase over time, because this volatility is affected by compounded, rather than annual, returns. Consequently, guarantee volatility rises over time, rather than being diversified away over longer investment periods.

Figure 3 here

A closer examination of Figure 3 reveals that, for investment periods longer than 25 years, volatility estimates become unstable, due to the paucity of return data for long investment periods. Over the post-WWII period, there are at best two independent observations for the 30year period returns. ${ }^{14}$ Clearly, data limitations weaken confidence regarding the claim that stocks outperform bonds over long-term investment periods. Experts using data from other countries also suggest that the US pattern is an exception, since other countries exhibit much

\footnotetext{
${ }^{13}$ Samuelson (1963) initially referred to this idea as the fallacy of large numbers; see also Bodie (1995).

${ }^{14}$ When analysts use 30 -year moving averages over the post-WWII period, these are not independent draws from the underlying distribution. This point has been made by various authors including Bodie (2001).
} 
smaller long-term equity premiums. ${ }^{15}$ Further, past data may be a rather poor predictor of future performance, so extrapolating the potential costs of a guarantee from this data can be deceptive.

\section{Illustrating Guarantee Values}

To provide a better understanding of the factors determining guarantee costs, this section presents and analyzes several examples. We show how pension guarantee costs depend on three key factors: the relation between the guarantee formula and the benefit structure, the volatility of the investor's portfolio, and the interaction between these two elements and the investor's investment horizon.

Five examples of guarantee designs help us explore the interactions between guarantee formulas and benefit structures. The first three IA guarantee designs we discuss are examples of a minimum rate of return guarantee, differentiated according to the rate of return guaranteed. Example 1 illustrates the cost of providing a principal guarantee, one that promises the participant the return of his contributions at retirement (equivalent to a zero nominal interest rate). Example 2 offers a real principal guarantee, one that promises the participant the return of his contributions with an adjustment for purchasing power at retirement (equivalent to a zero real interest rate). Example 3 provides the participant a guarantee that his individual account provides his principal plus a minimum interest rate equal to a 10 -year Treasury bond return.

Two additional examples are taken from the minimum benefit family of guarantees. Examples 4 and 5 consider a "mixed" system of social security benefits such as the one

\footnotetext{
${ }^{15}$ For example Jorion and Goetzmann (1999) conclude that the US equity market had "the highest uninterrupted real rate of appreciation of all countries, at 4.3 percent annually from 1921 to 1996 . For other countries, the median real appreciation rate was 0.8 percent. The high return premium obtained for US equities therefore appears to be the exception rather than the rule."
} 
described in general terms in Section II. ${ }^{16}$ In this context, we refer to $S S_{T}$ as "present law benefits", or the benefits projected according to the formulas in effect under the traditional social security system. The social security benefit formula does not currently incorporate any minimum or floor benefit on its own. Hence the guarantees provided in Examples 4 and 5 ensure that the retiree receives a total payment equal to the larger of the present law benefit or the poverty line. $^{17}$

It will be recalled that in a "mixed" system, the retirement benefit consists of the sum of the annuity $S S_{T}^{R E D}$ and a payment from the Individual Account $I A_{T}$. In Example 4, as we have constructed it, the plan participant may invest 2 percent of his earnings to an Individual Account, in lieu of paying social security taxes in that amount. Example 5 considers a larger IA system, where the participant can contribute 6 percent of his earnings to an IA. For both examples, in exchange for its participation in the IA, the participant's annuity is obtained by subtracting an "offset" from the present law benefits, i.e. $S S_{T}^{R E D}=S S_{T}-O f f S e t_{T}$. This offset is equivalent to the participant's IA contributions accumulated at the 3-month T-bill rate of return. ${ }^{18}$

The current social security benefit formula is progressive, providing low earners a higher replacement rate though a lower dollar amount, as compared to higher earners. The guarantee formulas examined here promise different replacement rates by income level, as compared to

\footnotetext{
${ }^{16}$ This analysis does not incorporate the financing required to move to a fiscally solvent system, since estimates of that cost are available elsewhere. Thus this exercise estimates the marginal cost of providing a guarantee for an Individual Account program, rather than the cost of restoring the first pillar system to solvency. Details of the schematic model used to represent the first pillar system appear in the Appendix. These two cases are examples selected to identify the drivers of guarantee costs; neither coincides with proposals devised by the President's Commission to Strengthen Social Security. In that group's report, the first pillar plan was assumed to be reformed with the advent of IAs, and IA contribution rates as well as offset rates were set to bring fiscal solvency to the system as a whole. Our goal here is not to establish costs of moving to solvency, but rather to outline the magnitude and sensitivity of guarantee costs to different guarantee designs.

${ }^{17}$ To qualify for the poverty line minimum, the participant must contribute at least 30 years to the annuity component of the system.

${ }^{18}$ Neither of these examples corresponds to specific plans outlined by the President's Commission to Strengthen Social Security. In particular, the Commission included no guarantees in its proposed reforms. Our objective here is to describe generic alternatives that help think about guarantees, rather than to cost any specific proposal.
} 
present law. We illustrate this sensitivity to earnings levels in Example 4 by contrasting the guarantee costs for two hypothetical workers: one at medium earnings level corresponding to the Social Security system's Average Wage Index (AWI), and another at a low earnings level representing 45 percent of this amount. Guarantee costs are also influenced by how the participant invests his IA account. To show this, we develop guarantee cost estimates for three alternative IA portfolios: one fully invested in equities; a second one invested half in equities and half in bonds; and a third held all in bonds. The role of the investment horizon is depicted through the use of four different contribution periods, with IA contributions occurring over, respectively $10,20,30$, and 40 years.

For each of the variations just listed, Tables 1,2, and 3 express the cost of providing the guarantee in question, for the specific investment mix, earnings level, and saving horizon illustrated. These costs are computed using the valuation method outlined in Section II and presented in a variety of units: as a percent of assets (Table 1), in present value dollars (Table 2), and as a percentage of lifetime contributions (Table 3). (The Appendix details the assumptions underlying the calculations.) Throughout this section, we refer mainly to Table 1 's costs expressed in basis points (hundredths of a percent of assets) because it is conventional to refer to costs associated with managing retirement accounts in those terms. However, this measure does not readily reflect changes in costs associated with varying the contribution rate or the investment horizon. Hence, for some purposes, we explore present value dollar costs from Table 2.

\section{Guarantee Formula and Benefit Structure}

For ease of discussion, we take as the base case a participant with a 50/50 stock/bond portfolio and a 40-year investment horizon. For such an investor, Line 8 of Table 1 shows that 
the cost of guaranteeing the 10-year Treasury bond return (Example 3) would be 0.65 percent of assets annually, or 65 basis points (bp). Alternatively, this is worth $\$ 3,406$ in present value dollars (Table 2), or equivalently, 16 percent of total contributions (Table 3). To understand why the guarantee is expensive, it is helpful to look at the anticipated gap between the value of the guarantee and the benefits provided by the IA. ${ }^{19}$ In the base case, the expected values of the Individual Account and the guarantee are equal. ${ }^{20}$ Therefore, guarantee payments will be generated as soon as the IA portfolio provides a below-mean return.

In the cases of Examples 1 and 2, the principal and real principal guarantees, the guaranteed amounts represent, respectively, only 30 percent and 52 percent of the expected IA value. Consequently the IA's investment performance would have to be significantly worse than expected before any guarantee would be paid; those payments will also be smaller in size as compared to Example 3. This translates into lower guarantee costs, as illustrated in Line 8 of Table 1: the guarantee costs drop to 0 and $2 \mathrm{bp}$ respectively. Of course guarantee costs this low indicates that such guarantees provide limited protection against investment risk. Although we have ignored administrative costs associated with the guarantee, in this case it is interesting to note that such fees could even exceed the guarantee payments themselves.

Continuing with the base case and moving along Line 8 , we next consider the minimum benefit guarantees of Examples 4 and 5. Recall that for these examples, the minimum benefit is defined as the US present law benefit, plus a poverty line minimum income. Here the expected gap between the guarantee and the retiree's benefits is influenced by the participant's lifetime

\footnotetext{
${ }^{19}$ This concept is equivalent to the concept of "moneyness" in option pricing. When the strike price of an option is set equal to the stock price, the option is said to be "at-the-money" and its cost is solely driven by volatility. When the strike price of a put option is larger (smaller) than the stock price, the option is said to be "in-of-the-money" ("out-the-money"). In those cases, volatility is not the only factor driving value and these options can be respectively very cheap or expensive.

${ }^{20}$ The term "expected value" refers to the risk-adjusted expected value used to determine the guarantee cost.
} 
earnings level. ${ }^{21}$ For the low earner, the guarantee represents from 100 percent to 120 percent of expected benefits under the mixed system, whereas this ratio is always 100 percent for the medium income earner. It is worth noting that the minimum benefit guarantee in this case introduces benefit improvements unrelated to the provision of investment risk protection. To see this, we note that the guarantee is costly even when the low earner invests his IA entirely in a bond portfolio: as indicated in Table 1, providing a minimum benefit for the low earner investing only in bonds still costs from 6 bp to 29.38 percent of assets.

Finally, costs are also influenced by the size of the IA account. To illustrate this, Examples 4 and 5 compare two different systems, one with an IA contribution rate of 2 percent and the other with a contribution rate of 6 percent. A larger Individual Account introduces more risk, which in turn results in higher costs for the guarantee. The guarantees cost the same amount in basis points (Table 1) but these are based on higher contributions and higher assets. To better judge the value of the guarantee, dollar costs are presented in Table 2, where Line 8 shows that as the contribution rate is tripled from 2 to 6 percent, the present value of guarantee costs are also tripled, rising from $\$ 3,401$ to $\$ 10,204$. This confirms that a minimum benefit guarantee in the context of a larger investment account is more costly.

\section{Volatility of the Investment Portfolio}

The illustrations also reveal that meeting a guarantee threshold is more likely if the Individual Account is invested in more volatile assets; thus boosting the allocation in equities always results in greater guarantee costs. For instance, when we move from the base case with a $50 / 50$ stock/bond mix to a portfolio invested all in equities, the cost of the guarantee doubles from 65 to 127 bp (Table 1, Example 3, Lines 4 versus 8). Reducing the fraction in equities to

\footnotetext{
${ }^{21}$ In any mixed system, participants' earnings levels will influence guarantee costs; more generally, guarantee formulas and guaranteed benefits are likely to interact nonlinearly with earnings.
} 
zero eliminates guarantee costs in the Example 3 case, of course, because the IA portfolio cannot do worse than the guaranteed benefit.

This implies that giving IA participants a choice over investment mix could be costly, in that they might boost the guarantee value by selecting a riskier investment portfolio. In general, it would be dangerous to provide participants with an IA guarantee without placing restrictions on their portfolio mix. However, Table 1 reveals that, for some guarantee designs, the impact of the investment portfolio on costs is less than in the base case. When guarantees are either very likely or very unlikely to be exercised, their costs are less sensitive to the portfolio allocation.

\section{Interaction with Investment Horizon}

As mentioned in Section II, some observers contend that lengthening the investment horizon might result in lower guarantee costs, because they believe that investment risk decreases over time. A different perspective is provided by Samuelson (1963) and Bodie (1995), who show that a put option guaranteeing the risk-free rate becomes more expensive as the investment horizon widens. In practice, the relation between guarantee costs and investment horizon proves to be complex, as Table 2 reveals. This relation is determined by the evolution over time of the two factors defined in this section: the relation between the guarantee formula vs. the benefit structure, and the IA volatility.

It will be recall that, in the base case, the expected value of the guarantee formula and the IA are equal, which implies that the guarantee costs are only driven by volatility. As the investment horizon lengthens, so too does the size of the IA and its volatility. And since guarantee costs increase with volatility, the cost of the guarantee would be expected to rise with the investment horizon. Comparing Lines 5 and 8 of Table 2, we see that lengthening the investment horizon from 10 to 40 years in Example 3 results in costs rising more than 
proportionally, from $\$ 570$ to $\$ 3,406$. On the other hand, the cost of the principal guarantees (Examples 1 and 2) falls with time, rather than rising. This is because under the principal guarantee, the guarantee value falls as a percent of the IA from 71 to 30 percent as the time period is extended from 10 to 40 years. The fact that the guarantee becomes less generous over time dominates the volatility effect and explains why the principal guarantee costs fall over time. Similarly, for the low earner in Example 4, the social security annuity grows over time at a faster rate than does the poverty line, which makes it less likely that the guarantee will pay off for the longer holding period.

\section{Financing Pension Accumulation Guarantees}

Proposals to include guarantees in an Individual Account model must specify not only their costs, as outlined above, but also how they could be financed. Financing decisions include several aspects:

- Who will bear the guarantee costs? (e.g. participants, taxpayers)

- Who will manage the guarantee and how? (e.g. private sector, government agency)

- What will the price structure be? (e.g. one price for all, prices differentiated by earnings level, portfolio mix, time horizon, etc)

This section examines several issues related to these three questions.

\section{Guarantee Financing: Pay-as-you-go vs. Self-Financed}

Feldstein and Liebman (2001) have suggested that the risk associated with guarantees could either be shifted to future taxpayers or transferred to private markets. ${ }^{22}$ One way to pay for an IA guarantee is to allow participants to elect self-financed guaranteed choices from a menu of

\footnotetext{
${ }^{22}$ As a variant, they also mention the "collar" strategy of Feldstein and Ranguelova (2000). With this strategy, the guarantee is financed by participants who give up some of the upside return potential of the IA's investment return. Smetters (2002) also describes a similar financing strategy.
} 
investment options. Financial institutions could offer "guaranteed return accounts" in the set of investment choices for people willing to pay for them. In this case, participants desirous of a guaranteed investment product would pay the premium, irrespective of whether the government or the private sector managed the accounts. (In Germany and Japan, private financial services firms are slated to provide the guaranteed accounts.)

An advantage of the self-financing approach to guarantees is that those who most value the enhanced security would also be those who would pay for it. Less risk-averse people would not have to subsidize the more risk-averse. In addition, since guarantee value and guarantee costs rise with the size of the portfolio being guaranteed in this context, financing would be more expensive for higher earners with larger accounts. Having those who value guarantees most pay for them avoids the poor potentially having to subsidize the risk-averse rich.

A potential disadvantage of self-financing guarantees is that some low-wage earners might value a guarantee more highly, yet they would be least able to afford it. Financing guarantee costs for the poor, in this case, might require subsidizing low-income savers out of general revenue. This might be feasible, but it also might detract from the appeal of guaranteed accounts to the extent that additional revenue would have to be identified to pay for them. Even in this case, however, it is critical to note that guarantee costs do not disappear just because the federal government shoulders them. Failing to report economic costs and benefits of guarantees cannot avoid the reality that economic resources are still at risk under the guarantee, and value is being transferred to participants.

If guarantee costs were passed on to future taxpayers instead of having participants selffinance them, it would mean that future taxes would have to be devoted to the system when guarantees were "in the money." A major problem with this tactic is that the guarantor could be 
asked to pay out precisely when economic conditions times were bleak. This could occur if the stock market and the economy collapsed at the same time, for instance. In such a circumstance, taxpayers might be unable or unwilling to raise taxes on themselves to cover the guarantees, even if promises had been made in the past. In other words, it is incorrect to assume that the federal government has "deep pockets" and can simply raise taxes on future workers to cover shortfalls whenever Individual Account investments perform poorly.

Indeed, one might ask whether such guarantees could be any more reliable than present social security promises. The law has established that traditional social security benefit promises are payable only when revenues are sufficient to cover them (Fleming v. Nestor, 1960). A similar point could be made about any form of guarantee: in a massive economic downturn, the promises would be worth no more than could be paid. A related issue is that supporters of Individual Accounts often state that these accounts are useful in building wealth and reducing unfunded tax claims on our children and grandchildren. Instituting guarantees without making them self-financed represents a new entitlement likely inconsistent with the reform philosophy.

\section{The Choice of a Guarantee Provider}

Although a guarantee resembles an insurance contract, its underlying risk is not diversifiable; hence, it cannot be managed with traditional insurance "pooling" techniques. Figure 1 shows that the guarantee payments are asymmetric and this shape is preserved even when guarantee payments of all IA participants are aggregated. This shape cannot be replicated by simply depositing the premiums into an insurance fund. However if these premiums were used to purchase the appropriate financial instruments, it would be possible to obtain the desired structure of payoffs. As an example, Bodie (2001) discusses how investment accumulation 
products could be guaranteed with the use of a combination of capital market instruments. ${ }^{23}$ In the eventuality that these products are not available in the capital markets, ${ }^{24}$ their payoffs could be replicated by applying option pricing techniques to a portfolio of appropriate securities.

When the guarantee payoffs can be replicated by the derivative strategy just described, either the government (or one of its agencies) or private providers would be able to offer the guarantee. $^{25}$ In practice, several elements of the guarantee contract cannot be hedged in capital markets (e.g. lifetime earnings, retirement age, etc.) To deal with this issue, one might imagine financial services firms offering contracts that are standardized in terms of earnings, portfolio mix, retirement age, and so forth. This approach has the advantage of reducing moral hazard, but it also subjects the participant to more risk due to the difference between his idiosyncratic situation and the standardized case (the "basis risk," in the options literature). If guarantees were not standardized, it would become more difficult for private providers to manage these contracts and it becomes more likely that the government would provide the guarantee. This is because the government may be better able to transfer losses to future generations, as compared to financial institutions. Such constraints could be mitigated if the private providers had access to reinsurance. Finally, if the guarantees featured some element of subsidy, private providers would be unable to manage the entire program without additional support.

\section{Price Structure}

The illustrations in Section III showed that the price of a guarantee is sensitive to the individual investor's characteristics and to his portfolio allocation. Consequently, a welldesigned pricing strategy should avoid the creation of opportunities for adverse selection and

\footnotetext{
${ }^{23}$ In this paper, we describe the guarantee as a put option on the IA. By "put-call parity", the combination of this put option and of the IA is equivalent to Bodie's strategy of investing in bonds and call options.

${ }^{24}$ Alier and Vittas (2001) discuss some alternative strategies to reduce IA risk when it is not possible to manage this risk via the capital markets.

${ }^{25}$ Some private providers already offer guarantees with their investment accumulation products, see Francis (2001).
} 
moral hazard. In this context we have already mentioned the need to have the guarantee linked to a specific IA portfolio mix. Depending on the guarantee structure, providers too can be subject to moral hazard. Making the guarantee provider responsible for asset allocation provides an incentive to invest in safer assets (Jensen and Sorensen, 2000). In Colombia, for instance, the guarantee premium under the IA program is not adjusted for risk; partly as a result, only 0.3 percent of the funds were invested in shares (as of December 1996; Fischer, 1999)).

\section{Discussion and Conclusions}

Opponents of Individual Accounts tend to understate the problems facing underfunded national pay-as-you-go social security systems, overlooking the fact that reductions in outlays and increases in revenues will be required to close the future financing gap. It is precisely the social security system's looming insolvency that makes current systems politically risky. Including Individual Accounts in a national social security reform plan can strengthen old-age economic security. These accounts can reduce the political risk confronting aging Americans when they assess the chances of actually receiving promised benefits under the insolvent social security system. These accounts also afford participants the opportunity to save in a costeffective manner, and to diversify their investments in ways that they may not be able to at present.

Nonetheless, there may be concern among policymakers that Individual Account participants will face capital market risk, particularly if they concentrate their accounts in stock market investments in the pursuit of higher returns. One approach to this problem is to restrict the extent of equities allowed in workers' accounts; another is to offer guarantees. 
This paper has explored several guarantee designs and assessed their likely costs. It shows that offering guarantees on such accounts can be costly even when participants are restricted to holding no more than half their portfolio in stock and the rest in bonds. In this case, a 10-year Treasury bond return guarantee would still require increasing annual contributions by 65 basis points, or 16 percent of contributions, for the long-term saver. This would likely be perceived as a substantial cost increase over and above the basic contribution by most plan participants. If these costs were not self-financed, substantial subsidies would be required. Subsidies of this sort must be measured, recognized, and their financing implications spelled out in detail for a full accounting of the economic costs and benefits of guarantees.

These cost estimates might seem high to people accustomed to the argument that stock returns are expected to outperform bond returns over time. We argue, however, that because of the paucity of independent observations in historical data on long holding periods, past returns are noisy predictors of future returns. In addition, guarantee costs are driven by stock and bond volatility rather than their expected returns. 


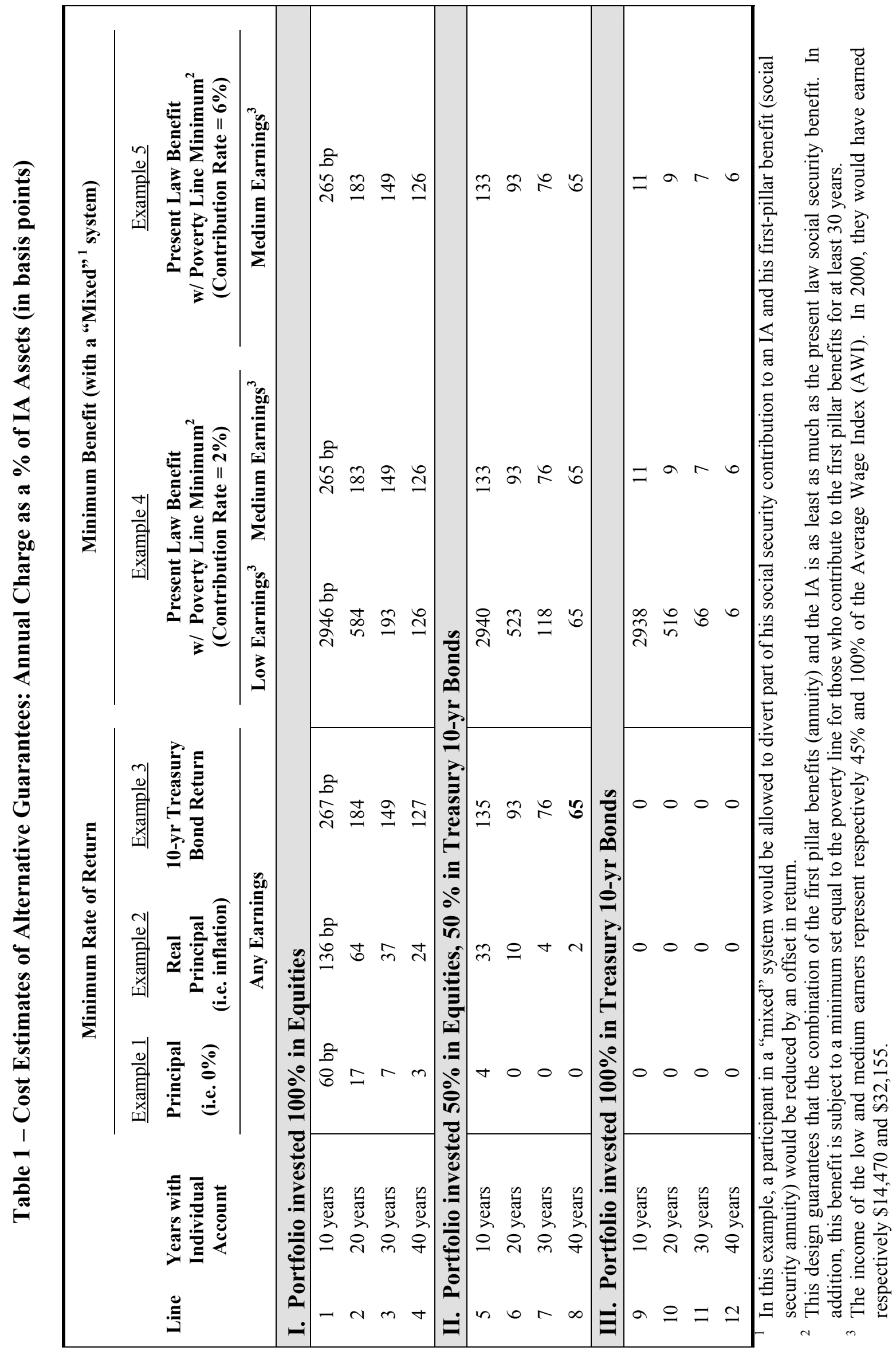




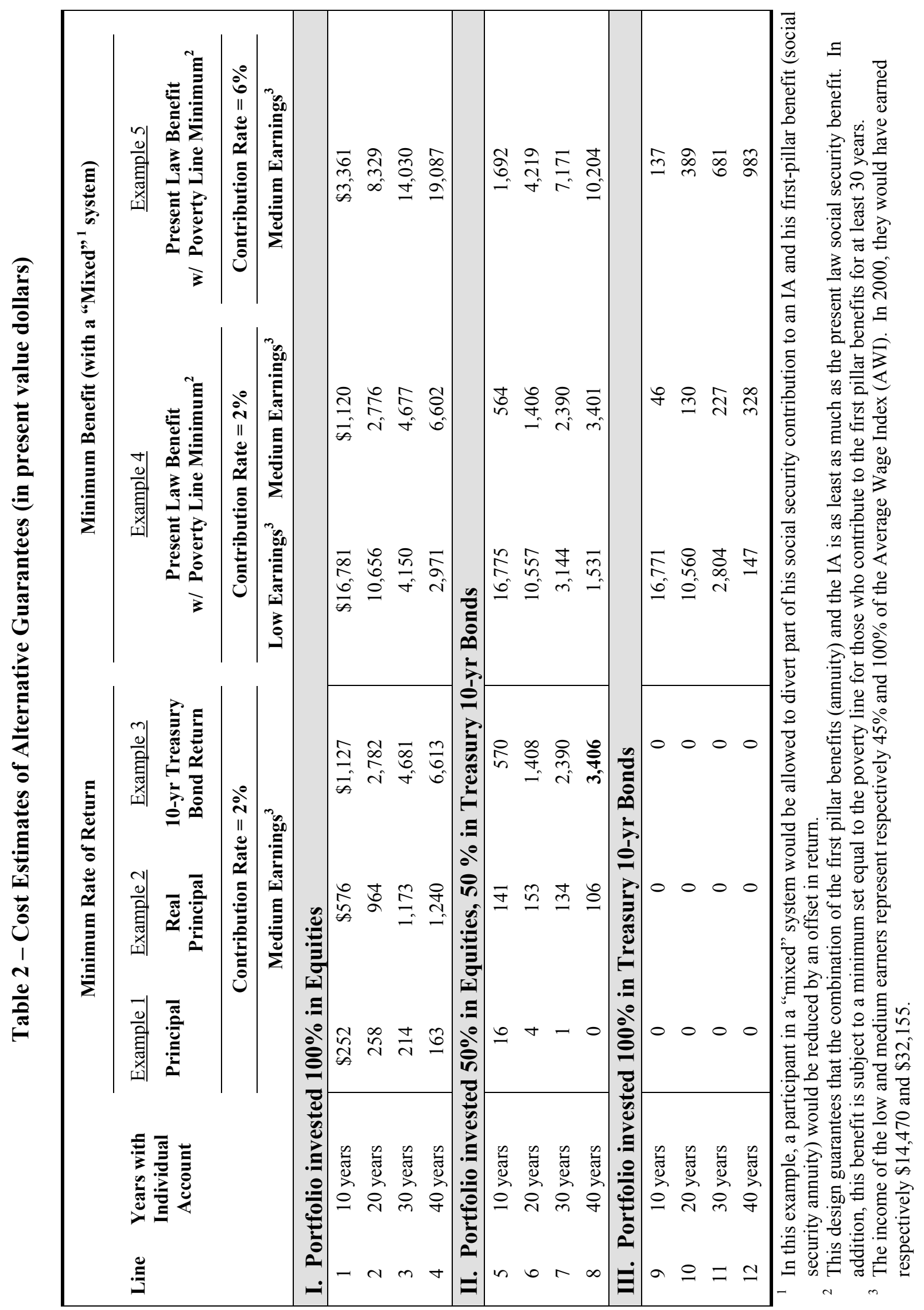




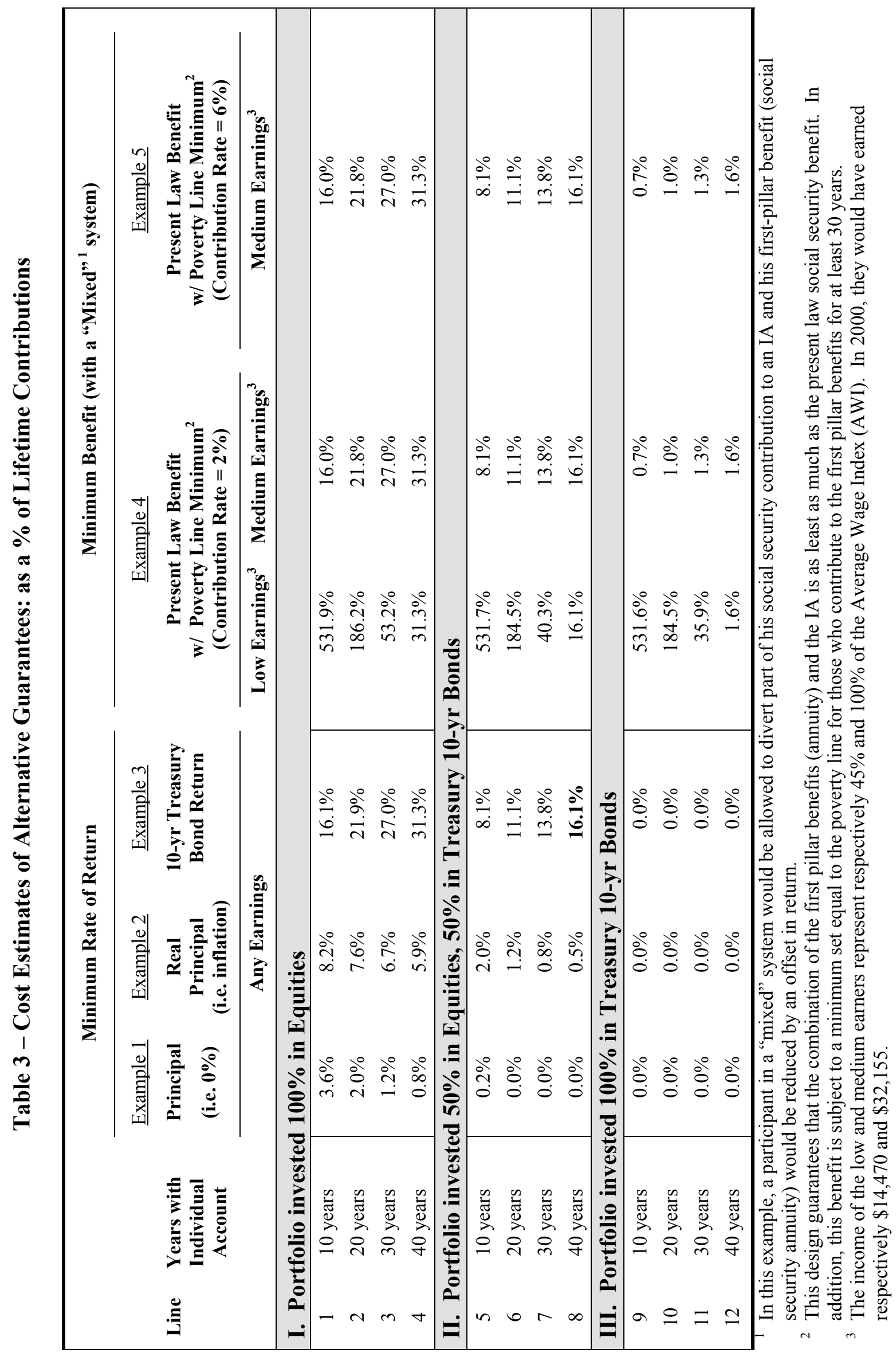


Figure 1. Guarantee Payments as a Function of the Individual Account Value

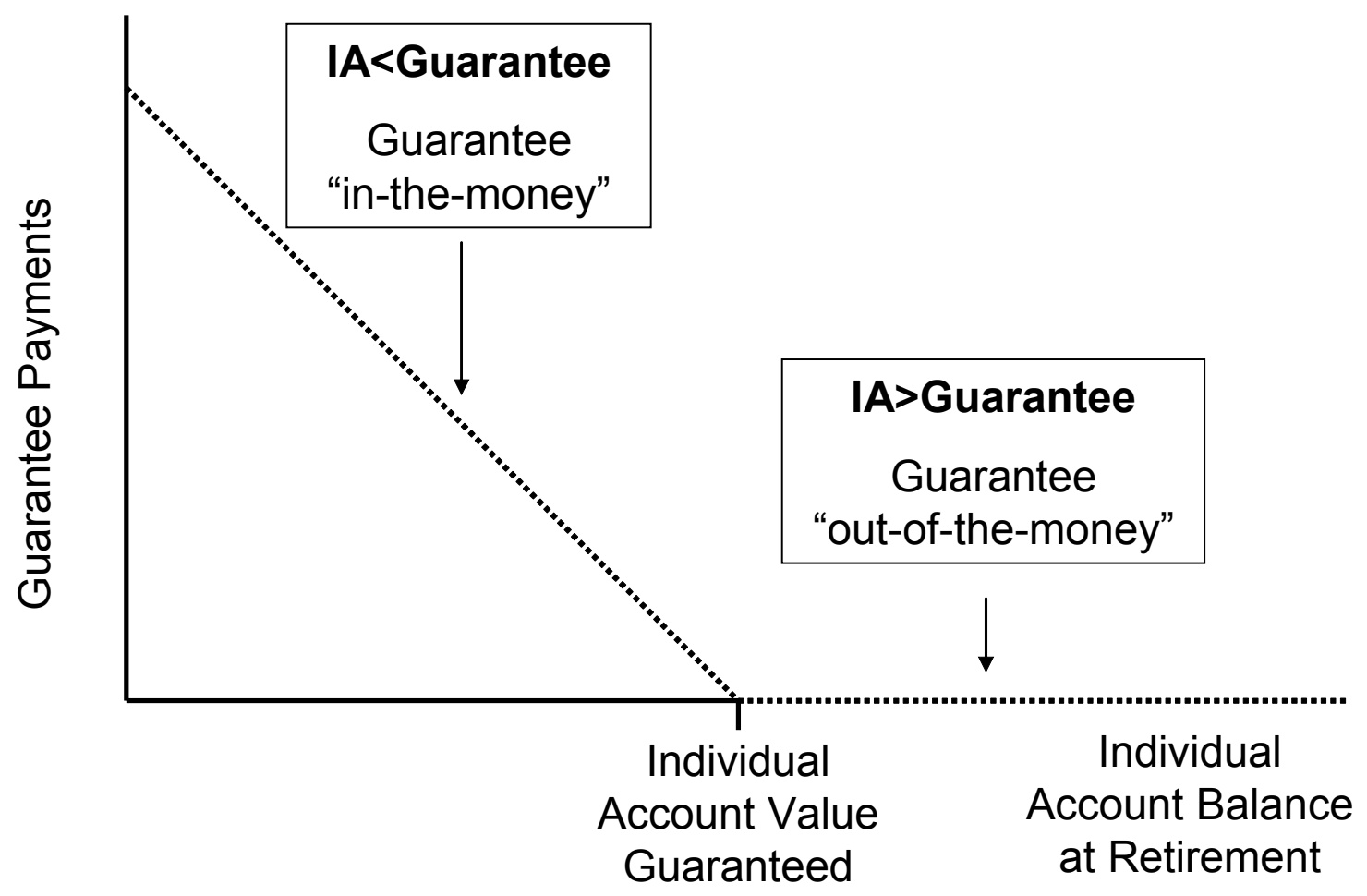


Figure 2: Annual Returns for US Stock and Bond Markets, 1942-2000

Source: Authors' computations, data from CRSP; historical annual stock returns from S\&P 500 index including dividends; bond returns from an index of 10-year Treasuries.

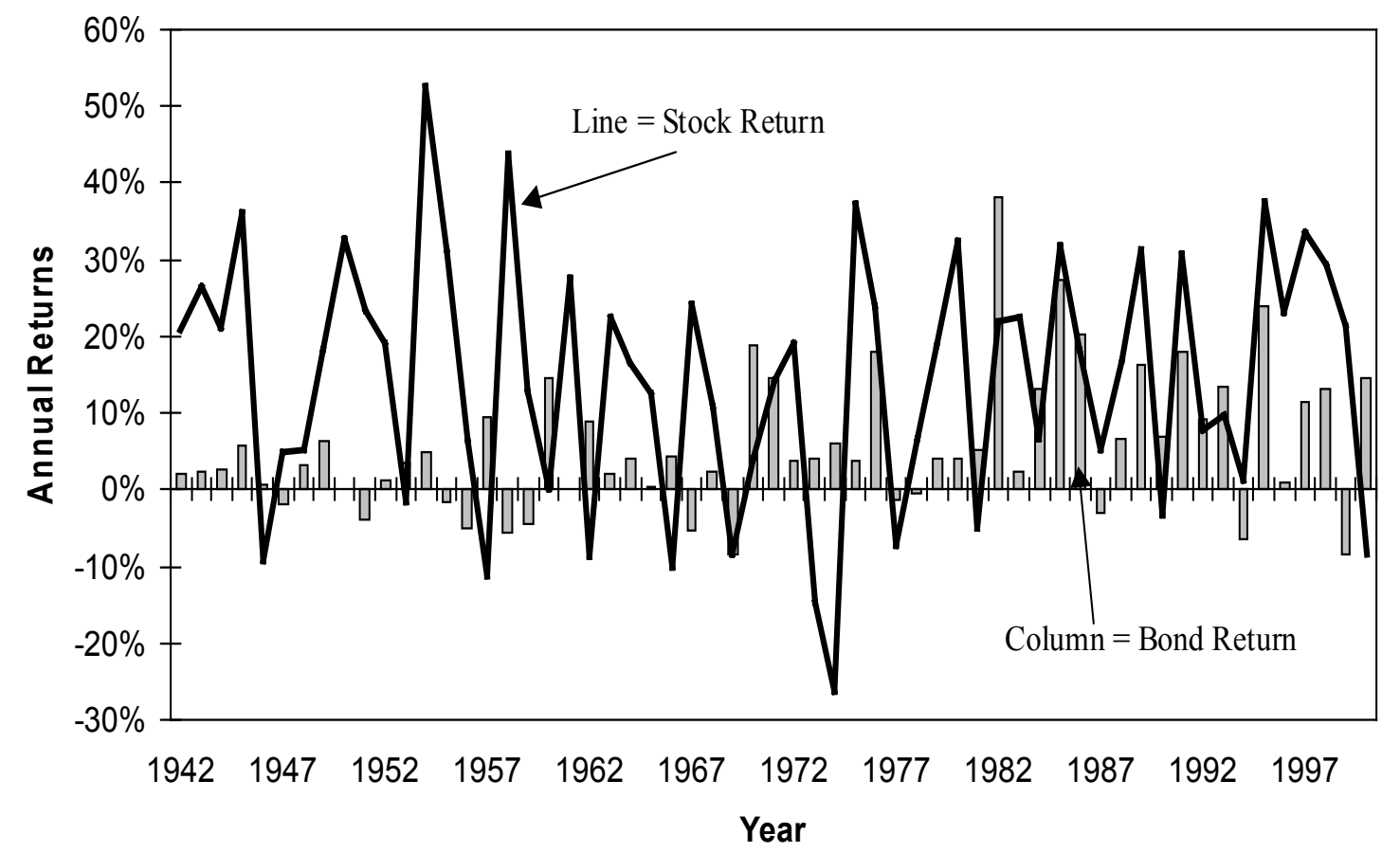

Figure 3: The Effect of Longer Time Horizons on the Volatility of Stock Returns Source: Authors' computations using data described in Figure 2.

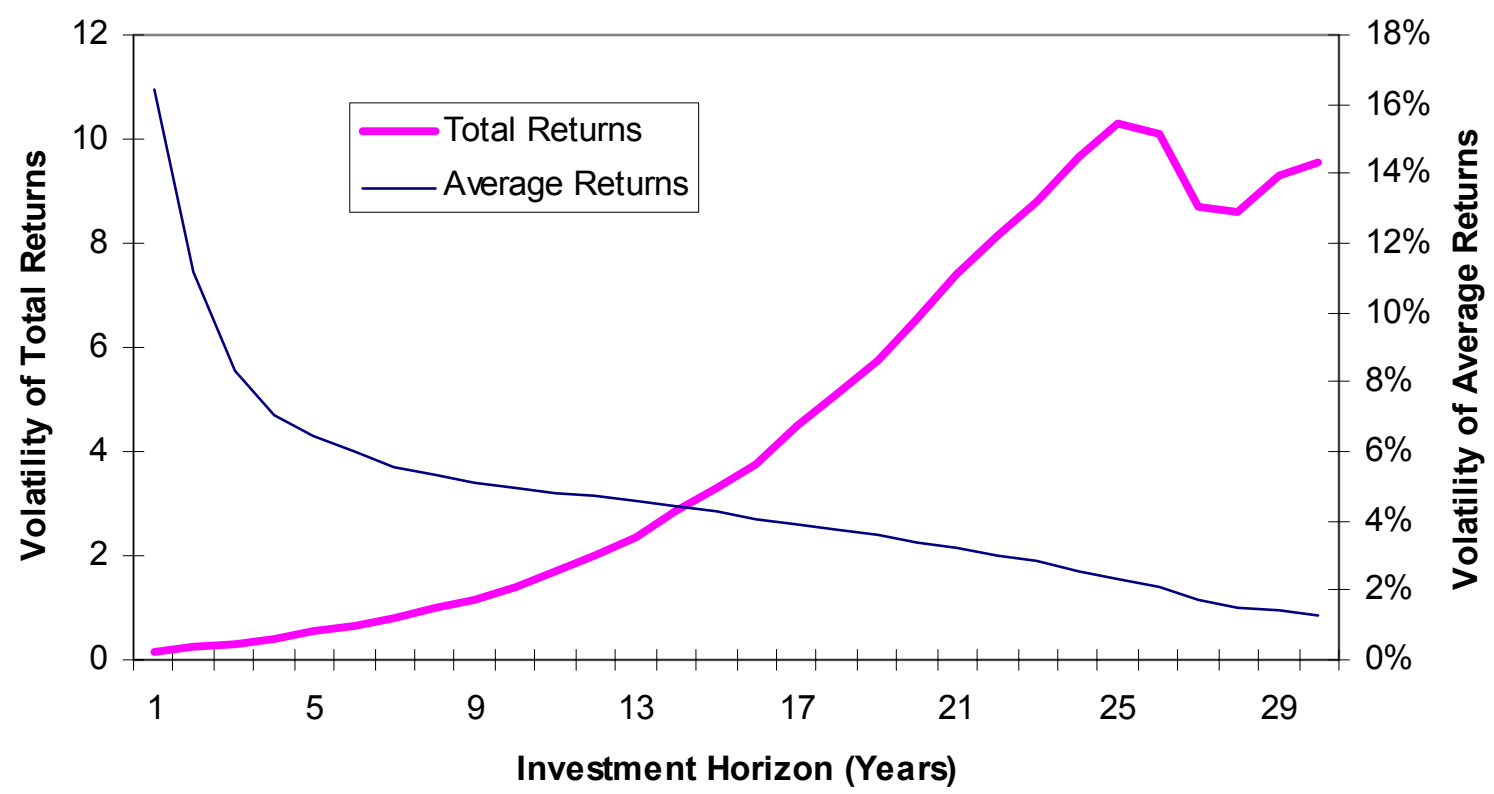




\section{References}

Alier, Max and Dimitri Vittas, "Personal Pension Plans and Stock Market Volatility", Development Research Group, World Bank. Eds. R. Holzmann and J.E. Stiglitz. New Ideas About Old Age Security. Washington, D.C.: World Bank, 2001.

Benson, Miles. "Social Security Compromise Would Guarantee Benefit Levels." New York Times, November 19, 2001.

Black, F. and M. Scholes. “The Pricing of Options and Corporate Liabilities.” JPE, 1973, 81 (3): 637-54.

Bodie, Z. "Financial Engineering and Social Security Reform." In Risk Aspects of Social Security Reform. Eds. J. Campbell and M. Feldstein. Univ. of Chicago Press, 2001.

Bodie, Z. "On the Risk of Stocks in the Long Run”. Financial Analysts Journal, May/June 1995.

Bodie, Z. and R. Merton. "Pension Benefit Guarantees in the United States: A Functional Analysis." In The Future of Pensions in the United States. Ed. R. Schmitt. University of Pennsylvania Press, 1993.

Clark, Robert L. and Olivia S. Mitchell. "Strengthening Employment-Based Pensions in Japan”. Benefits Quarterly, Second Quarter 2002: 22-43.

Commission to Strengthen Social Security. CSSS. Strengthening Social Security and Creating Personal Wealth for All Americans, 2001.

Duffie, Darrell. Dynamic Asset Pricing Theory, 1996, Princeton University Press.

Feldstein, Martin and Elena Ranguelova. "Accumulated Pension Collars: A Market Approach to Reducing the Risk of Investment-Based Social Security Reform.” NBER Working Paper 7861, August 2000.

Feldstein, Martin and Andrew Samwick. "Potential Paths of Social Security Reform". NBER Working Paper 8592, November 2001.

Feldstein, Martin and Jeffrey B. Liebman. "Social Security”. NBER Working Paper 8451, September 2001.

Fischer, Klaus P. 1999. “Pricing Pension Fund Guarantees: A Discrete Martingale Approach.” Canadian Journal of Administrative Sciences, 16(3), 256-266.

Francis, Theo. “Guaranteed Funds Give Skittish Security.” Wall Street Journal. June 8, 2001.

Hull, J. Options, Futures, and Other Derivatives, Third Edition, 1997 Prentice-Hall.

Jensen, Bjarne Astrup and Carsten Sorensen. "Paying for Minimum Interest Rate Guarantees: Who Should Compensate Who?" Working paper 2000-1, Copenhagen Business School.

Jickling, Mark. "The Enron Collapse: An Overview of Financial Issues", Congressional Research Service, February 4, 2002.

Jorion, Philippe and William Goetzmann. "Global Stock Markets in the Twentieth Century", Journal of Finance, 54(3) June 1999: 953-980.

Maurer, Raimond and Christian Schlag.. "Money-Back Guarantees in Individual Account Pensions: Evidence from the German Pension Reform." Presented at the Pension Research Council Conference, Wharton School, April 2002. 
Mitchell, Olivia S. and Stephen Utkus. "Company Stock and Retirement Plan Diversification." 2002. Pension Research Council, Wharton School.

OASDI Board of Trustees, Annual Report of the Board of Trustees of the Federal Old-Age and Survivors Insurance Trust Funds, March 19, 2001.

Pennachi, George G. "The Value of Guarantees on Pension Fund Conversion.” Journal of Risk and Insurance, 1999, $66(2), 219-237$.

Pennachi, George G. "Methodology to Assess Fiscal Risk of Pension Guarantees." Working Paper. University of Illinois. May 2000.

Samuelson, Paul. "Risk and Uncertainty: A Fallacy of Large Numbers.” Scientia 98 1963: 1-6.

Siegel, Jeremy. Stocks for the Long Run. McGraw Hill. 1998.

Smetters, Kent. "Controlling the Costs of Minimum Benefit Guarantees in Public Pension Conversions." The Journal of Pension Economics and Finance, 1(1), March 2002.

Smetters, Kent. "The Effect of Pay-when-needed Benefit Guarantees on the Impact of Social Security Privatization". In Risk Aspects of Social Security Reform. Eds. J. Campbell and M. Feldstein. Univ. of Chicago Press, 2001.

Zarita, Salvador. "Minimum Pension Insurance in the Chilean Pension System." Revisita de Analisis Economico, 1994, 9(1): 105-126. 


\section{Appendix: An Illustration of Option-Pricing Techniques Applied to Individual Accounts}

This Appendix details the modeling assumptions used to derive cost estimates for the illustrative examples discussed in the text. We summarize guarantee costs for four workers who participate in the Individual Accounts (IA) program for, respectively, $T=10,20,30$, and 40 years. It is assumed that the IA starts in 2004 and economic variables are projected accordingly. Sections A and $\mathrm{B}$ of this Appendix describe the economic and demographic assumptions. The stochastic processes followed by the bills, bonds, and stocks are modeled separately in Section C. Section D details the elements necessary to compute the IA values as well as the social security annuity. Section E derives the value of each guarantee formula while Section F shows how to generate numerical values for the guarantee costs using a Monte Carlo simulation.

\section{A. Economic Assumptions}

All projections are expressed in nominal values, with the inflation and real processes modeled separately. Assumptions for inflation growth, real wage growth, and real interest rates are taken from the OASDI Annual Report (2001). In that report, the intermediate scenario assumes that real wage growth is $g=1.0 \%$, while inflation grows at $i=3.3 \%$. By combining these two assumptions, the result is a $4.3 \%$ nominal wage growth assumption. According to the intermediate scenario, the real interest rate assumption is $r^{R E A L}=3 \%$. This fixed interest rate assumption is used for the annuity calculation in Section B, while the remaining calculations use the stochastic model of Section C.

At the inception of the IAs, earnings levels are denoted by $W_{0}$. In subsequent years, earnings $W_{t}$ are obtained by projecting these initial earnings with a fixed rate of $4.3 \%$. Two categories of wages are used in the simulations: the medium earner correspond to the Social Security Actuary's Average Wage Index (AWI) while a low earner represents $45 \%$ of this amount. For instance, the low and medium earners would have received respectively $\$ 17,785$ and $\$ 32,155$ in $2000 .^{26}$ Finally, according to the US Census Bureau, the poverty line for singles over 65 years old was \$8,494 in 2001, a level assumed to grow with the Consumer Price Index (CPI) over time.

\section{B. Demographic Assumptions}

The four illustrative cases are assumed to be, respectively, 22, 32, 42, and 52 years old at the inception of the IA system. Each participant is assumed to retire at the early retirement age of 62 years old. At this age, the value of a $\$ 1$ annuity with payments indexed to inflation is denoted by the annuity factor $\ddot{a}_{62}$. To compute this annuity factor, it is necessary to define survival

probabilities after retirement. The standard notation ${ }_{t} p_{62}$ is used to denote the probability that an individual retiring at age 62 would still be alive at age $62+t$. Post-retirement survival probabilities are derived from the Social Security 1997 period life table ${ }^{27}$ (pre-retirement mortality is not included in the model). As for the real interest rate used to discount the annuity payments, it is taken from the OASDI intermediate scenario. Letting the last age (radix) of the mortality table be represented by $\omega$, the value of the annuity factor is given by:

\footnotetext{
${ }^{26}$ No adjustment for age is made, since the AWI is an average measure for workers of all ages. Hence, earnings are likely overestimated for younger participants and underestimated for older ones.

${ }^{27}$ Available at www.ssa.gov/OACT/STATS/table4c6.html.
} 


$$
\ddot{a}_{62}=\sum_{t=0}^{\omega-1-62}\left(1+r^{R E A L}\right)^{-t}{ }_{t} p_{62} .
$$

\section{Stochastic Processes (risk-adjusted)}

a. Risk-Free Rate:

The continuous risk-free rate is defined by Vasicek's (1977) mean reverting model:

$$
d r_{t}=\kappa\left(\mu-r_{t}\right) d t+\sigma d W_{t}^{r}
$$

where $d W_{t}^{r}$ is a standardized Wiener process and the initial risk-free rate is given by $r_{0}=r$. According to Hull (1997), the current term structure should lead directly to the risk-neutral process for interest rates and the necessary risk-adjustments are incorporated in (8). For estimation and simulation purposes, it will be useful to take advantage of the fact that the Vasicek model leads to the following normal representation of the risk-free rate:

$$
\begin{gathered}
r_{t} \mid r_{t-1}=\mu\left(1-e^{-k}\right)+e^{-k} r_{t-1}+\sigma \sqrt{\left(1-e^{-2 \kappa}\right) / 2 \kappa} \varepsilon_{t} \\
\varepsilon_{t} \sim N(0,1) .
\end{gathered}
$$

Equation (9) corresponds to a simple regression and its parameters can be estimated by OLS. For this estimation, the risk-free rate is represented by the 3-month T-Bill annual time series for the period 1980-2001. The period between World War II and October 1979 is excluded due to the Federal Reserve policy of stabilizing interest rates at the time. Using this data, the OLS parameters estimates are respectively $r_{0}=2 \%, \hat{\kappa}=80 \%, \hat{\mu}=3.0 \%$, and $\hat{\sigma}=2 \%$. The annual risk-free rate values can then be simulated by generating a series of error terms $\varepsilon_{t}$ and substituting them into equation (9).

b. Bond Returns:

To compute the bond portfolio return, we take advantage of the direct relation between the movements of the risk-free rate and bond returns. The bond portfolio is invested in 10-year Treasury zero coupon bonds, assumed to be rebalanced annually. The same assumptions apply to the 10-year Treasury guarantee in Example 3. When it is computed with the Vasicek model, the price at time $t$ of a bond with time to maturity $\tau$ can be represented as follows:

$$
\begin{gathered}
P\left(\tau, r_{t}\right)=e^{A(\tau)-B(\tau) r_{t}} \\
\text { where, } \quad A(\tau)=(B(\tau)-\tau)\left(\mu-\frac{\sigma^{2}}{2 \kappa^{2}}\right)-\frac{\sigma^{2} B(\tau)^{2}}{4 \kappa} \\
B(\tau)=\frac{1-e^{-\kappa \tau}}{\tau} .
\end{gathered}
$$

Since it is assumed that the 10 -year bond fund is rebalanced annually, its annual return $B_{t}$ is given by the percentage increase in price after one year: 


$$
B_{t}=\frac{P\left(9, r_{t+1}\right)}{P\left(10, r_{t}\right)}-1,
$$

where $r_{t}$ and $r_{t+1}$ are generated by (9). Note that there is no relation between the notations $B_{t}$ and $B(\tau)$.

c. Stock Returns:

Letting $S_{t}^{I}$ represent the stock index level at time $t$, the continuous stock returns are modeled by the following geometric Brownian motion:

$$
\frac{d S_{t}^{I}}{S_{t}^{I}}=r_{t} d t+\sigma d W_{t}^{S}
$$

where $d W_{t}^{S}$ is a standardized Wiener process which we assumed to be uncorrelated with the one in equation (8). Following the risk-neutral valuation technique, the drift of the return process in (12) is set equal to the risk-free rate. In addition, let $S_{t}$ denote the annual stock return in year $t$. Then $S_{t}$ is distributed according to a lognormal distribution and can be represented by:

or, equivalently

$$
\ln \left(1+S_{t}\right)=r_{t}-\sigma^{2} / 2+\sigma \varepsilon_{t}, \quad \text { where } \varepsilon_{t} \sim N(0,1)
$$

$$
S_{t}=\exp \left(r_{t}-\sigma^{2} / 2+\sigma \varepsilon_{t}\right)-1
$$

To estimate the parameter $\sigma$, we note that equation (13) is normally distributed with standard deviation $\sigma$. The usual estimator can then be applied to obtain $\hat{\sigma}=20 \%$. Stock return data for the estimation were taken from the S\&P 500 Index (including dividends) during the period 19262000. Using this parameter estimate, the annual stock returns are simulated by generating a series of error terms $\varepsilon_{t}$ and substituting them into equation (14).

d. Investment Returns for Individual Accounts:

In this illustrative model, the worker is assumed to allocate his IA investments between two funds: an indexed stock fund and a bond fund (of 10-year Treasuries). Denote by $\alpha$ the proportion invested by the participant in the stock fund. Further, let $S_{t}$ and $B_{t}$ represent the total return at time $t$ for each of the funds. It follows that the portfolio investment rate of return in year $t$ is given by:

$$
R_{t}=\alpha S_{t}+(1-\alpha) B_{t}
$$

In Tables 1, 2 and 3, the results are generated for three alternative portfolios with $\alpha=0 \%$, $\alpha=50 \%$, and $\alpha=100 \%$.

\section{Retirement Benefits Structure: Social Security Benefits and Individual Account Payouts \\ a. Social Security Annuity:}


Denote by $S S A_{T}$ the annuity payment that a participant would receive if he retired at age 62 , under a stylized annuity benefit formula similar to, though not completely identical to, current law formulas. The first input to the benefit formula is the $A I M E_{T}$, or Average Indexed Monthly Earnings. Here we assume that the last 35 (annual) earnings are used in the $A I M E_{T}$ calculation. These are indexed with wage growth up to age 60 , with the exception of the last two earnings values.

$$
A I M E_{T}=\frac{W_{T-1}+W_{T-2}+\sum_{i=T-35}^{T-3} W_{t}((1+i)(1+g))^{T-2}}{35}
$$

The social security benefit formula involves the use of two "bendpoints," indexed to the AWI and referred to below as $F B P_{T}$ and $S B P_{T}$. In 2002, the annualized bendpoints were, respectively, $\$ 7,104$ and $\$ 42,804$. Present law benefits are computed by multiplying the $A I M E_{T}$ by $90 \%$ for the portion below the first bendpoint, and by $32 \%$ and $15 \%$ for the portions respectively below and above the second bendpoint. Finally, the retiree's benefits are subject to an early retirement reduction factor, denoted by $E R R_{T}$. According to SSA, $E R R_{T}=75 \%$ for the participant with $T=10$ and $E R R_{T}=70 \%$ for the other participants. The following formula summarizes the benefit calculation.

$$
S S A_{T}=E R R_{T} \times\left(\begin{array}{lll}
90 \% \times \min \left(A I M E_{T}, F B P_{T}\right) & \\
+32 \% \times\left(\min \left(A I M E_{T}, S B P_{T}\right)-F B P_{T}\right) & \text { if } & \left.F B P_{T} \leq A I M E_{T}\right) \\
+15 \% \times\left(A I M E_{T}-S B P_{T}\right) & \text { if } & \left.S B P_{T} \leq A I M E_{T}\right)
\end{array}\right.
$$

The value of the first pillar social security benefit $S S_{T}$ is then obtained by multiplying (17) by the annuity factor: $S S_{T}=S S A_{T} \cdot \ddot{a}_{62}$.

b. Individual Account Payouts :

In all models considered but one, system participants are permitted to divert $2 \%$ of their taxable earnings to an Individual Account. (The exception is Example 5 where participants are allowed to contribute $6 \%$ of taxable earnings). Letting $C$ represent the fixed contribution rate, then the dollar contribution in year $t$ is given by $C_{t}=C \cdot W_{t}$. The value of the Individual Account at retirement is represented by $I A_{T}$. This value is computed as:

$$
I A_{T}=\sum_{t=0}^{T-1} C_{t} \prod_{j=t}^{T-1}\left(1+R_{j}\right)
$$

where $R_{j}$ was defined in Section C.

c. Social Security Benefits for Individual Account Participants: 
Those who participate in the IAs reduce their contributions to the Social Security Trust Fund, so their first pillar benefits are offset in exchange. For the present case, we compute the offset by accumulating IA contributions with a stated rate of return $R^{O}$,

$$
\operatorname{Offset}_{T}=\sum_{t=0}^{T-1} C_{t}\left(1+R_{t}^{O}\right)^{T-t}
$$

For this analysis we set $R_{t}^{O}=\exp \left(r_{t}\right)-1$; i.e., the offset rate is defined as the risk-free rate. It follows that the expected present value of the reduced benefits, denoted by $S S_{T}^{R E D}$, is given by the following formula:

$$
S S_{T}^{R E D}=S S_{T}-O f f s e t_{T}
$$

The participant is then assumed to receive the sum of his Individual Account and the reduced social security annuity, or $I A_{T}+S S_{T}^{R E D}$.

\section{E. Guarantee Formulas}

a. Rate of Return Guarantees:

Let $R_{t}^{G}$ represent the guaranteed rate of return for any of the rate of return guarantees described in the text. Then $G_{T}$, the value of the guarantee at retirement, is given by:

$$
G_{T}=\sum_{t=0}^{T-1} C_{t} \prod_{j=t}^{T-1}\left(1+R_{j}^{G}\right)
$$

For the principal guarantee and the real principal guarantee, we have respectively $R_{t}^{G}=0 \%$ and $R_{t}^{G}=i \%$. Letting $B_{t}$ represent the bond return again, the 10-year Treasury guarantee is modeled using $R_{t}^{G}=B_{t}$. For each of these examples, the guarantee payments are obtained by comparing $G_{T}$ and $I A_{T}$.

\section{b. Minimum Benefit Guarantees:}

For Examples 4 and 5, let $G_{T}$ represent the present value of the guaranteed annuity. Denoting by $P L_{T}$ the value of a poverty line annuity at retirement, then $G_{T}=\max \left(S S_{T}, P L_{T}\right)$. The guarantee payments are obtained by comparing this amount to the "mixed" system benefit payment $I A_{T}+S S_{T}^{R E D}$.

\section{F. Risk-Neutral Valuation and Monte-Carlo Simulations}

The results in the text are obtained by simulating the value of equation (4) using the appropriate definition of the guarantee payoffs $f_{T}$ from equations (1) and (3). Cost estimates are obtained by using 10,000 Monte Carlo simulations. For Tables 1 and 3, these costs are divided, respectively, by $\sum_{t=0}^{T-1} \hat{E}\left[e^{-\bar{r} t} C_{t}\right]$ and $\sum_{t=0}^{T-1} \hat{E}\left[e^{-\bar{r} t} I A_{t}\right]$ to obtain the appropriate units. 